\title{
Avaliação Ecotoxicológica da Estação de Tratamento de Esgotos Suzano (São Paulo) Utilizando Daphnia similis e Vibrio fischeri
}

\author{
N. Hamada ${ }^{1}$, L. C. A. Mesquita ${ }^{1}$, I. W. Pereira ${ }^{2}$, E. Nakano ${ }^{3}$, S. I. Borrely ${ }^{1 *} \&$ L. F. Tallarico 3 \\ ${ }^{1}$ Instituto de Pesquisas Energéticas e Nucleares, Centro de Tecnologia das Radiações, \\ Av. Lineu Prestes, n. 2242, Cidade Universitária, CEP 05508-000, São Paulo - SP, Brasil \\ ${ }^{2}$ Companhia de Saneamento Básico do Estado de São Paulo - SABESP \\ ${ }^{3}$ Laboratório de Malacologia, Instituto Butantan
}

(Received August 27, 2008; Accepted November 29, 2010)

\begin{abstract}
RESUMO
O aumento demográfico e o desenvolvimento industrial geram contaminação aos recursos hídricos muito acima da sua capacidade de autodepuração. A agência responsável pelo monitoramento ambiental, CETESB, prioriza 27 locais para abastecimento de água na região do Alto Tietê. Poucos são os dados de toxicidade disponíveis em Estações de Tratamento de Esgotos em São Paulo. Este trabalho avaliou efeitos agudos de 5 amostras de afluentes e efluentes da ETE Suzano coletadas entre Setembro de 2005 e Março de 2008 em Daphnia similis e Vibrio fischeri. Os resultados mostraram que para D. similis a toxicidade foi reduzida totalmente pelo tratamento, enquanto que ensaios com $V$. fischeri resultaram em toxicidade remanescente e cuja eficiência média foi de 57,90\%. Comparação entre estudos revelaram melhor situação atual, refletindo esforços da Cia. de Saneamento Básico do Estado de São Paulo (SABESP) no controle de recebimento de efluentes e na manutenção da operação da ETE.

Palavras-chave: Daphnia similis, efluentes, ETE Suzano, toxicidade, Vibrio fischeri.

ABSTRACT

Ecotoxicity Assessment of Suzano Wastewater Treatment Plant (São Paulo) Using Daphnia Similis and Vibrio Fischeri

Population growth and industrial development generate pollution to water resources far above their assimilation capacity. The environmental control agency, (CETESB) ensures 27 sites for monitoring toxicity at Tietê River (Alto Tietê), and priority is given to water supply sources. Few data is available on toxicity monitoring of waste water treatment plant (WWTP) from São Paulo. The objective of this study was to evaluate the toxicity of affluent and effluent of Suzano WWTP, assessing the reduction in toxicity. Five samples were taken from September 2005 to March 2008. A complete removal of acute toxicity for D. similis was obtained but for Vibrio fischeri the efficiency of treatment was not the same. With this luminescent bacteria, the average efficacy of SWWTP was $57.90 \%$. Comparison among studies evidenced less toxicity in the present as a result of some efforts done by the São Paulo Water and Sewage Company (SABESP).
\end{abstract}

Keywords: Daphnia similis, effluents, wastewater treatment plant, toxicity, Vibrio fischeri.

* Corresponding author: Sueli Ivone Borrely, e-mail: sborrely@ipen.br. 


\section{INTRODUÇÃO}

A escassez de água tem sido um dos principais problemas do século XXI, o que torna indispensável tanto a preservação das águas quanto seu uso racional, por tratar-se de um recurso natural vital. O Brasil possui água em abundância, mas distribuída de forma desigual. Na metrópole paulista há escassez de água. A região é abastecida por oito sistemas produtores e atende 28 milhões de pessoas, aproximadamente (Mananciais, 2009). O desenvolvimento industrial e o crescimento demográfico geram altos níveis de poluição nos corpos d'água, com descartes de efluentes industriais que possuem compostos químicos orgânicos e inorgânicos, metais, metalóides, pesticidas, radionuclídeos, matéria orgânica dos esgotos, além de surfactantes, nitrogênio e fósforo, entre outros possíveis contaminantes (Rand,1995), os quais causam danos à biota. A ETE Suzano é uma das cinco estações de tratamento de esgotos da Região Metropolitana de São Paulo, e seu efluente é lançado no Rio Tietê, cujo trecho está classificado como classe 3 segundo critérios do CONAMA 357 (2005).

Segundo o relatório de qualidade de águas interiores do Estado de São Paulo (CETESB, 2007), a qualidade da água para abastecimento público é ruim no trecho Alto Tietê à jusante da ETE Suzano. Na avaliação do índice de vida aquática (IVA), esse mesmo trecho foi classificado como péssimo. Os níveis de coliformes termo-tolerantes estão cerca de 4 a 70 vezes acima do estabelecido pela Resolução CONAMA 357 (2005).

A ETE Suzano recebe esgotos municipais, chorume de aterro municipal e efluentes industriais de composição diversificada em função das atividades produtivas da região, principalmente. Do total de afluentes recebidos e tratado, cerca de $20 \%$ são industriais. Estudos do final da década de 80 , na mesma região, indicaram que as indústrias químico-farmacêuticas representavam as principais cargas orgânicas, seguidas pelas indústrias têxteis (Zagatto \& Goldstein, 1991). A ETE Suzano está localizada relativamente próxima da nascente do Rio Tietê, merecendo estudos que visem sua preservação com redução de cargas orgânica e tóxica. Existe ampla legislação estadual e federal buscando proteger os corpos receptores de efluentes, sendo que algumas incluem o parâmetro toxicidade, como a Resolução Estadual SMA 03 (SMA, 2000) no Estado de São Paulo e no âmbito federal, a CONAMA 357 (2005). Com base nessa legislação, o lançamento de efluentes no rio não poderia introduzir efeitos na biota. Entretanto, vários trechos no Rio Tietê encontram-se praticamente anóxicos em partes da coluna d'água e com contaminantes nos sedimentos (CETESB, 2007).

Aparentemente, o papel principal do tratamento de esgotos e efluentes tem sido a remoção de matéria orgânica, cuja eficiência está próxima a $80 \%$ com o tratamento secundário (CESTESB, 2007). Estudos mostram que a situação dos rios continua ruim, mesmo com elevada eficiência das estações na remoção da matéria orgânica (CETESB, 2007; Hamada, 2008). A contaminação das águas por compostos orgânicos e inorgânicos é prejudicial tanto para a eficiência das estações de tratamento como para a biota do corpo receptor, que é afetada por excesso de nutrientes, baixos teores de oxigênio dissolvido nas águas, incapacidade de alimentação de organismos, equilíbrio e reprodução reduzidos na biota e o efeito tóxico propriamente. Ao tomar os detergentes como exemplo, sabe-se que estes estão presentes nas ETEs em concentrações importantes ( $3 \mathrm{a}>10 \mathrm{ppm}$ ). Efeitos agudos do surfactante dodecil sulfato de sódio e de detergentes foram evidenciados por $\mathrm{CE}_{50}$ (15 minutos) de 1,92 ppm para $V$. fischeri e $\mathrm{CL}_{50}$ (96 horas) igual a $0,030 \mathrm{~mL} . \mathrm{L}^{-1} \mathrm{em}$ peixes Brachydanio rerio (Romanelli, 2004; Pereira et al., 1987).

Tendo como função a limpeza, os surfactantes atingem o sistema biológico por alvos variados, causando alteração na permeabilidade da membrana celular, no processo de fosforilação prejudicando o desenvolvimento microbiano; já no rio induzem eutrofização e redução nas trocas gasosas, entre outros efeitos. Estimativas sugerem que as ETEs conseguem reduzir cerca de um terço do total de surfactantes dispostos nas águas e boa parte atinge águas e sedimento de rio, mar e ambiente terrestre. Redução importante da microfauna nos sistemas de lodos ativados pode ser induzida pela presença de surfactantes em concentrações relativamente baixas (<10 mg. $\left.\mathrm{L}^{-1}\right)$ (Rand, 1995). A ETE Suzano apresenta um histórico importante da presença de surfactantes. A partir de três estudos de toxicidade aguda dessa ETE foram obtidos em 25 ensaios agudos com $D$. similis, no efluente final CE(I) $)_{50}$ médio de 28,34\% (Pereira et al., 1987). Entre 1998 a 2001, ensaios para efeito agudo em $D$. similis evidenciaram eficiências entre 56 e $78 \%$ para a redução de toxicidade. Entretanto, em algumas amostragens foram observados valores de toxicidade aguda muito elevada, se considerado um efluente tratado, o qual também é recebido pelo Rio Tietê. Esses valores corresponderam a $\mathrm{CE}(\mathrm{I})_{50}$ de 1,15, 2,07 e 9,33\% (agosto de 99, setembro de 99 e abril de 2000, respectivamente) (Borrely et al., 2002). Resultados de toxicidade em Vibrio fischeri confirmaram os níveis de toxicidade determinados. A utilização de $D$. similis e $V$. fischeri nesta avaliação justificou-se por serem estes mesmos organismos utilizados em outros estudos.

O objetivo do presente trabalho consistiu em avaliar a toxicidade aguda em afluentes e no efluente final tratado do sistema de tratamento ETE Suzano entre Setembro de 2005 e Março de 2008, utilizando D. similis e $V$. fischeri e determinando a eficiência do sistema de tratamento para a remoção de toxicidade.

\section{MATERIAL E MÉTODOS}

\section{Estação de tratamento de esgotos - ETE Suzano}

Situada a $52 \mathrm{~km}$ da cidade de São Paulo, opera desde 1982, pelo processo de lodos ativados, em nível secundário e com grau de eficiência superior a 90\% na remoção de carga orgânica. Essa estação é operada pela Companhia de Saneamento Ambiental do Estado de São Paulo (SABESP), sendo projetada para 720.000 habitantes. A estação recebe entre 10 a 20\% de sua vazão em efluentes industriais, sendo que $7 \%$ de um determinado efluente com alto teor de aminas (Spósito, 2006).

\section{Amostragem}

A fim de estimar a carga tóxica que adentra a estação e se existe toxicidade residual no efluente tratado foram amostrados dois pontos localizados na ETE Suzano sendo eles Grade Fina 
(AGF) e o Efluente Final (EF), durante duas estações de chuva e seca, totalizando cinco coletas. O efluente da grade média é o afluente a ser tratado na estação e que já passou pela redução dos sólidos mais grosseiros. A SABESP realizou a coleta das amostras e fez a composição das mesmas (quatro alíquotas em 24 horas de coletas, com proporcionalidade de vazão de entrada). Estas foram coletadas entre setembro de 2005 (C1) até março de 2008 (C5), e as intermediárias em julho de 2006 (C2); fevereiro e agosto de 2007 (C3 e C4).

\section{Ensaios de toxicidade}

Os ensaios ecotoxicológicos foram realizados no Laboratório de Ensaios Biológicos Ambientais do Instituto de Pesquisas Energéticas e Nucleares (LEBA) com o cládocero Daphnia similis e a bactéria luminescente Vibrio fischeri, conforme NBR 12713 (ABNT, 2004) e NBR 15411-2 (2006).

A diluição serial das amostras para os ensaios de toxicidade compreendeu o intervalo entre 25 a $100 \%$ de amostra para exposição de dafnídeos (Daphnia similis), além do controle (água de cultivo natural). $\mathrm{O}$ tratamento de resultados empregou o programa estatístico Trimmed Spearman Karber para calcular a $\mathrm{CE}(\mathrm{I})_{50}$ (Hamilton et al., 1977).

Para os ensaios com bactérias $V$. fischeri as seguintes concentrações foram utilizadas: 24,26; 36,40; 54,60 e 81,90\% (ajuste de salinidade na maior concentração, o que reduz a maior concentração a $81,90 \%$ ). Cubetas de vidro neutro com $2000 \mu \mathrm{L}$ de diluente receberam $1000 \mu \mathrm{L}$ de amostra, seguida da homogeneização da solução. Algumas amostras necessitaram maior diluição. $\mathrm{O}$ cálculo da $\mathrm{CE}(\mathrm{I})_{50}$ foi realizado a partir de regressão linear entre os valores das concentrações e as respectivas reduções de luminescência, induzidas pelos contaminantes da amostra.

A partir da transformação dos valores de toxicidade obtidos, foi calculada a eficiência do tratamento biológico desses efluentes por meio da redução de unidades tóxicas (UT), utilizando a transformação da $\mathrm{CE}(\mathrm{I})_{50}$ em valores diretamente proporcionais, conforme a Equação 1.

$$
U T=\frac{100}{C E 50}
$$

Durante o programa de amostragem, alguns parâmetros físico-químicos foram analisados: temperatura, $\mathrm{pH}$, Oxigênio Dissolvido (OD), Demanda Bioquímica de Oxigênio (DBO), condutividade, carbono orgânico total, sólidos totais, fenol, nitrogênio, nitrogênio amoniacal, com metodologia sugerida no Standard Methods (APHA, 1998).

\section{RESULTADOS E DISCUSSÃO}

Os resultados apresentados compreendem um período de Setembro de 2005 a Março de 2008, onde uma mistura real de afluentes e efluentes tratados foram avaliados. Na Tabela 1 foram organizados os resultados de toxicidade para Daphnia similis, com 24 e 48 horas de exposição, e os de Vibrio fischeri na Tabela 2.

Na Figura 1 foram apresentados os valores de redução de Unidades de Toxicidade entre o afluente e efluente, que representa a eficiência da estação na remoção da toxicidade, para V. fischeri.

Entre as cinco coletas, os afluentes apresentaram toxicidade mais crítica para $D$. similis somente em 2005 (CE(I) $)_{50}$ de $0,60 \%$ ), o que mostra uma toxicidade muito elevada, quando a média obtida para as três coletas seguintes foi de $17,41 \%$ $( \pm 2,88)$ para 24 horas de exposição e $15,02 \%( \pm 3,47)$ para exposição de 48 horas. $\mathrm{O}$ valor obtido na quinta amostragem foi excluído da média e desvio padrão por apresentar uma toxicidade bem inferior quando comparada ao conjunto. Com relação ao efluente final (tratado), foi detectada toxicidade somente em duas amostras e com valores de $\mathrm{CE}(\mathrm{I})_{50}$ acima de $75 \%$, portanto muito menos tóxicos que os afluentes.

Com relação aos efeitos para a bactéria $V$. fischeri, em afluentes, o valor mais tóxico foi $1,02 \%$, em 2005 , e menos tóxico em 2008 (>81,90\%). Dos três resultados intermediários foi obtida uma média de $15,80 \%( \pm 2,16)$. Com relação à toxicidade do efluente tratado tem-se uma média das quatro primeiras amostragens de $31,20 \%( \pm 6,65)$ e o último valor de $81,90 \%$, o qual representa o melhor efluente do período estudado. A variabilidade de efeitos determinados durante o estudo é decorrente da complexidade dos efluentes que atingem a ETE Suzano, eficiência do sistema de tratamento e a diluição dos afluentes em estações chuvosas.

Comparando os resultados obtidos com os dois organismosteste verifica-se uma perfeita concordância em termos de comportamento, pois a primeira das cinco amostragens apresentou

Tabela 1 - Valores médios e intervalos de confiança de $\mathrm{CE}(\mathrm{I})_{50}$ obtidos com Daphnia similis em afluentes e efluentes da ETE Suzano.

\begin{tabular}{lccc}
\hline \multicolumn{1}{c}{ Coleta } & $\begin{array}{c}\text { Duração do } \\
\text { ensaio (hora) }\end{array}$ & $\begin{array}{c}\text { Grade fina } \\
\mathrm{CE}(\mathrm{I})_{50}(\%, \mathrm{v} / \mathrm{v})\end{array}$ & $\begin{array}{c}\text { Efluente final } \\
\mathrm{CE}(\mathrm{I})_{50}(\%, \mathrm{v} / \mathrm{v})\end{array}$ \\
\hline 1 $^{\mathrm{a}}$ & 24 & $0,60(0,49-0,74)$ & $\mathrm{NT}$ \\
(setembro/2005) & 48 & $0,60(0,49-0,74)$ & $\mathrm{NT}$ \\
$2^{\mathrm{a}}$ & 24 & $14,82(12,57-17,46)$ & 100 \\
(julho/2006) & 48 & $14,82(12,57-17,46)$ & 100 \\
$3^{\mathrm{a}}$ & 24 & $16,89(11,44-24,93)$ & $\mathrm{NT}$ \\
(fevereiro/2007) & 48 & $11,65(11,44-24,93)$ & $\mathrm{NT}$ \\
$4^{\mathrm{a}}$ & 24 & $20,52(16,85-24,98)$ & $75<\mathrm{CE}_{50}<100$ \\
(agosto/07) & 48 & $18,60(16,90-20,47)$ & - \\
5 $^{\mathrm{a}}$ & 24 & $83,84(58,98-119,17)$ & $\mathrm{NT}$ \\
(março/2008) & 48 & $71,19(59,92-54,58)$ & 75,65 \\
\hline
\end{tabular}

NT- Não Tóxico.

Tabela 2 - Valores médios e intervalos de confiança de $\mathrm{CE}(\mathrm{I})_{50}$ obtidos com Vibrio fischeri em afluentes e efluentes da ETE Suzano (exposição por 15 minutos).

\begin{tabular}{lcc}
\hline \multicolumn{1}{c}{ Coleta } & $\begin{array}{c}\text { Grade fina } \\
\text { CE(I) } 50(\%, \mathrm{v} / \mathrm{v})\end{array}$ & $\begin{array}{c}\text { Efluente final } \\
\text { CE(I)50 }(\%, \mathrm{v} / \mathrm{v})\end{array}$ \\
\hline $1^{\text {a }}$ & 1,02 & 36,01 \\
(setembro/2005) & $(0,96-1,09)$ & $(23,40-96,75)$ \\
$2^{\text {a }}$ & 18,23 & 28,01 \\
(julho/2006) & $(13,47-24,65)$ & $(12,78-61,37)$ \\
$3^{\text {a }}$ & 14,05 & 23,40 \\
(fevereiro/2007) & $(3,23-61,08)$ & $(45,95<\mathrm{CE} 50<81,90)$ \\
$4^{\text {a }}$ & 15,13 & 37,41 \\
(agosto/2007) & $(4,13-55,41)$ & $(7,19-194,73)$ \\
$5^{\text {a }}$ & $>81,90$ & $>81,90$ \\
(março/2008) & & \\
\hline
\end{tabular}


piores resultados para ambos. Nas três amostras seguintes as CE(I $)_{50}$ médias foram de $17,41 \%$ para $D$. similis e $15,80 \%$ para $V$. fischeri. Já, os resultados obtidos com o efluente final da ETE para a bactéria apresentaram toxicidade remanescente do tratamento que representa a existência de efeitos por algum contaminante. Ainda nesse período, a variação de $\mathrm{pH}$ das amostras afluentes e efluentes foi monitorada pois microcrustáceos e outros organismos não toleram fortes variações de acidez nas águas. Durante o período estudado foram obtidos valores de $\mathrm{pH}$ entre 7,12 a 7,27 considerando montante e jusante e $\mathrm{pH}$ entre 7,35 a 8,18 para afluentes e efluentes tratados. Portanto, verificou-se que existe correção prévia dos efluentes industriais antes de atingir o tanque de mistura na ETE.

De acordo com dados obtidos por Hamada (2008), nesse mesmo período do estudo o efluente final apresentou importante concentração para solventes orgânicos: xilenos e etilbenzeno $\left(55,0 \mu \mathrm{g} . \mathrm{L}^{-1}\right)$ e tolueno $\left(4,90 \mu \mathrm{g} \cdot \mathrm{L}^{-1}\right)$. Em termos de efeitos biológicos foram obtidos nos efluentes finais $\mathrm{CE}(\mathrm{I})_{50}$ entre $23,40 \%$ a $>81,90 \%$ em $V$. fischeri, no período. Essa toxicidade residual obtida com a bactéria luminescente resultou em eficiência da ETE inferior em relação àquela obtida para $D$. similis.

Considerando que para $D$. similis a toxicidade aguda fora praticamente reduzida na sua totalidade, (Tabela 1) a eficiência da estação para a redução da toxicidade fora calculada somente para Vibrio fischeri por meio da transformação de $\mathrm{CE}(\mathrm{I})_{50}$ a UT, sendo obtida uma redução média de 57,90\% (57,90 $\pm 28,25$, Figura 1). A toxicidade remanescente no efluente final tem sido detectada com certa frequência embora existam muitas evidências de que o sistema de gestão dessa ETE vem procurando monitorar os efluentes industriais que contribuem com a carga tóxica que entra nesse sistema de tratamento.

No década de 80 foi evidenciado que, mesmo após o tratamento, havia efeitos tóxicos remanescentes nessa estação (Zagatto \& Goldstein, 1991; Gherardi-Goldstein et al., 1993). Foram sugeridos tratamentos prévios em determinados efluentes industriais. Outros estudos mostraram que $79 \%$ dos efluentes domésticos e $62 \%$ dos efluentes industriais apresentavam efeitos tóxicos após os tratamentos para remoção de contaminantes

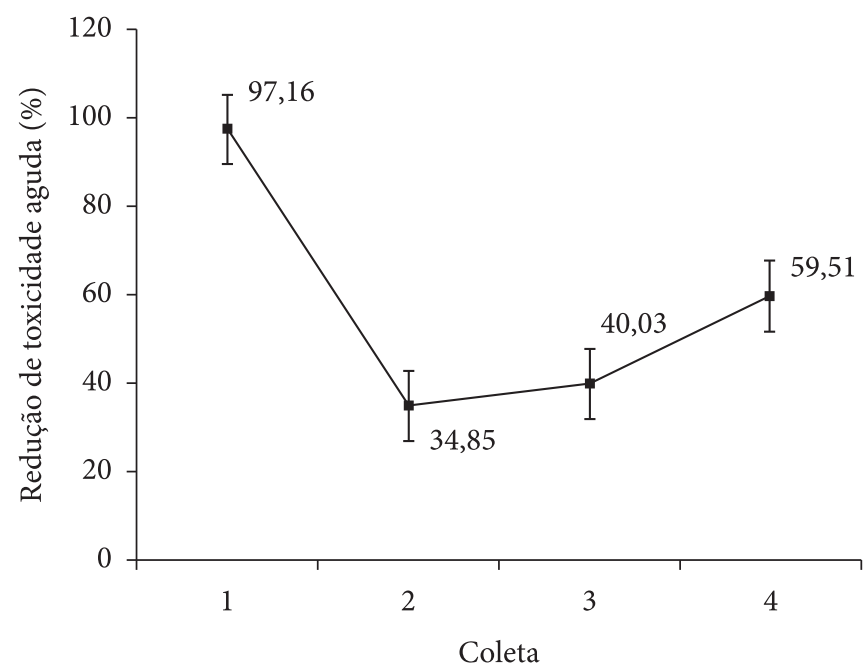

Figura 1 - Eficiência da ETE Suzano na redução da toxicidade aguda para V. fischeri. convencionais e que $43 \%$ dos domésticos e $46 \%$ dos efluentes industriais tinham potencial para causar efeitos tóxicos nos mais diferentes corpos receptores desses efluentes (Zagatto $\&$ Bertoletti, 2006).

Associada à presença de detergentes em efluentes e águas, assim como os esgotos, ocorre a presença excessiva de nitrogênio e fósforo. $\mathrm{O}$ nitrogênio tem sido um composto importante do ponto de vista de saneamento, suscitando ampla discussão em função de sua presença nas águas em virtude suas formas químicas e riscos que representam. Nos afluentes da ETE Suzano, o nitrogênio amoniacal variou praticamente o dobro entre as datas amostradas $\left(30-56,90 \mathrm{mg} . \mathrm{L}^{-1}\right)$. O mesmo se verificou nas águas do rio à jusante da ETE Suzano (2,90 - 7,10 mg.L. ${ }^{-1}$, variação em P4).

Analisando resultados anteriores da região estudada é possível destacar: redução de toxicidade durante o tratamento entre 50 e 86\%; apesar disso Gherardi-Goldstein et al. (1993) observaram que o efluente final possuía potencial para causar efeitos crônicos no rio Tietê (D. similis). Entre 1998 a 2001, em outro estudo que visava a aplicação de processo oxidativo avançado em efluentes da ETE Suzano, ensaios de toxicidade foram realizados por Borrely et al. (2002), sendo observada boa eficiência do tratamento para a redução de toxicidade em $D$. similis. Entretanto, foram encontrados valores de toxicidade muito elevados para um efluente tratado, também recebido pelo Rio Tietê $\left(\mathrm{CE}(\mathrm{I})_{50}\right.$ de 1,15, 2,07 e 9,33\% para D. similis em agosto de 99 , setembro de 99 e abril de 2000, respectivamente). Resultados de toxicidade em Vibrio fischeri do presente trabalho confirmaram os níveis de toxicidade determinados anteriormente.

Estes estudos mostraram ainda que a estação recebe concentrações importantes de surfactantes, mesmo sem que ocorra formação de espuma em excesso, existindo residual de surfactantes em efluentes tratados bem como no rio $\left(0,47 \mathrm{mg} . \mathrm{L}^{-1}\right.$ à jusante da ETE). Uma das razões para que o ensaio com V. fischeri resulte sempre em maior toxicidade nessa estação pode estar associada aos surfactantes, pois de acordo com a literatura, a $\mathrm{CE}(\mathrm{I})_{50}$ do dodecil sulfato de sódio é de 1,92 $\pm 0,40$ para $V$. fischeri e 11,81 $\pm 4,64$ para $D$. similis, enquanto que o linear alquilbenzeno de sódio, 13,49 \pm 4,54 (V. fischeri) e 4,56 $\pm 1,44$. Para efeito crônico (CEO) em $C$. dubia as concentrações de DSS e LAS foram de 5,30 e 3,00 mg.. $\mathrm{L}^{-1}$, respectivamente (Romanelli, 2004).

A exposição de caramujos adultos Biomphalaria tenagophila a nonifenóis etoxilados, surfactantes não iônicos, resultaram em efeito agudo para embriões e adultos e efeito crônico para a segunda geração (Oliveira-Filho et al., 2006). Peixes e invertebrados apresentam sensibilidade similar ao LAS (surfactante aniônico mais empregado), com efeito agudo a partir de 1 a 10 mg.L $\mathrm{L}^{-1}$, respectivamente (Rand, 1995).

A ETE ainda não consegue melhorar a condição insuficiente de oxigênio nas águas do rio, pois tanto à montante quanto $\mathrm{a}$ jusante a concentração de oxigênio dissolvido esteve sempre inferior a $1 \mathrm{mg} . \mathrm{L}^{-1}$ (Hamada, 2008). Por maior esforço tecnológico que seja empregado nos sistemas de tratamento, é fundamental o controle das fontes emissoras de efluentes em locais, como esse, com elevada industrialização e com reflexo importante na 
qualidade das águas. Deve também ser considerado que essa região necessite ampliar o atendimento aos esgotos domiciliares, sobretudo nos municípios de Guarulhos e Mogi das Cruzes.

A situação do ponto de vista de tratamento melhorou no país, mas é preciso muito cuidado com o recebimento de efluentes industriais pelas ETEs. É de conhecimento público que, mesmo sendo tratados, resíduos e sub-produtos de diferentes classes de contaminantes acabam sendo lançados aos rios, podendo induzir efeitos crônicos e mutagênicos aos organismos e contaminando fortemente os sedimentos.

\section{CONCLUSÕES}

Existe um aporte de toxicidade aguda que adentra o sistema de tratamento e que resulta em toxicidade residual que é diluída no Rio Tietê. Esse residual foi evidenciado somente para Vibrio fischeri. Dos dois organismos-teste utilizados nos ensaios de toxicidade a bactéria luminescente $V$. fischeri foi ligeiramente mais sensível quando comparada com $D$. similis.

Os resultados evidenciaram que a ETE Suzano tem conseguido controlar o aporte de toxicidade aguda que adentra o sistema de tratamento. A eficiência na redução de toxicidade tem sido melhorada temporalmente, podendo ser mais efetiva se maior volume de efluentes industriais forem monitorados quanto à toxicidade e submetidos a tratamentos prévios, quando necessário.

Agradecimentos - Nossos agradecimentos à FAPESP por financiar o projeto de pesquisa (05/60237-8) e SABESP pela parceria e coletas, além de toda a colaboração.

\section{REFERÊNCIAS BIBLIOGRÁFICAS}

ABNT, Associação Brasileira de Normas Técnicas, 2004, NBR 12713, Ecotoxicologia aquática: Toxicidade aguda - métodos de ensaio com Daphnia spp. (Cladócera, Crustácea). Rio de Janeiro, 21p.

ABNT, Associação Brasileira de Normas Técnicas, 2006, NBR 15411-2, Ecotoxicologia aquática: determinação do efeito inibitório de amostras de água sobre a emissão de luz de Vibrio fischeri (Ensaio de bactéria luminescente). Rio de Janeiro, 14p.

APHA, American Public Health Association, 1998, Standard methods for the examination of water and wastewater. $19^{\text {th }}$ ed. American Public Health Association, American Water Works Association, Water Environmental Federation, New York.

BORRELY, S. I., TORNIERI, P. H. \& SAMPA, M. H. O., 2002, Avaliação da toxicidade aguda em efluentes industriais, afluentes e efluentes de estação de tratamento de esgotos. In: E. L. G. Espíndola, C. M. R. Botta-Paschoal, O. Rocha, M. B. C. Bohrer
\& A. L. Oliveira-Neto (ed.), Ecotoxicologia: perspectivas para o século XXI. RIMA, São Carlos, SP. p.395-406.

CETESB, Companhia de Tecnologia de Saneamento Ambiental, 2007, Relatório de qualidade das águas interiores do Estado de São Paulo 2007. Governo do Estado de São Paulo, Secretaria do Meio Ambiente, Companhia de Tecnologia de Saneamento Ambiental, São Paulo, 540p.

CONAMA, Conselho Nacional do Meio Ambiente, 2005. Resolução $n^{\circ} 357$ de 17 de Março de 2005, Brasília, DF.

GHERARDI-GOLDSTEIN, E., BERTOLETTI, E., ZAGATTO, P. A., NAKAHIRA, S. \& INOUE, J., 1993, Dispersão de efluentes e os padrões ambientais. Ambiente, 7:12-17.

HAMADA, N., 2008, Ensaios biológicos empregados na avaliação da eficiência de sistemas de tratamento de esgotos e de efluentes. Dissertação (Mestrado)-Instituto de Pesquisas Energéticas e Nucleares, Universidade de São Paulo, São Paulo, 60p.

HAMILTON, M. A., RUSSO, R. C. \& THURFTON, R. B., 1977, Trimmed Spearman-Karber method for estimating median lethal concentration in toxicity bioassays. Environ. Sci. Technol., 11:714-719.

MANANCIAIS, 2009. Available from: <www.mananciais.org.br/ site/mananciais $>$. Access in: set. 2009.

OLIVEIRA-FILHO, E. C., GRISOLIA, C. K. \& PAUMGARTEN, F. J. R., 2006, Avaliação dos efeitos de baixas concentrações do nonilfenol etoxilato sobre a reprodução do caramujo aquático B. tenagophila: um estudo multigeração. In: IX Congresso Brasileiro de Ecotoxicologia. São Pedro.

PEREIRA, D. N., GOLDSTEIN, E. G., ZAGATTO, P. A. \& SASSI, R., 1987, Bioensaios: um programa a serviço do controle de poluição. Resultados iniciais. Ambiente, 1:32-36.

RAND, G. M., 1995, Fundamentals of aquatic toxicology: effects, environmental fate, and risk assessment. $2^{\text {nd }}$ ed. Taylor \& Francis LTD, London, 1125p.

ROMANELLI, M. F., 2004, Avaliação da toxicidade aguda e crônica dos surfactantes DSS e LAS submetidos à irradiação com feixes de elétrons. Dissertação (Mestrado)-Instituto de Pesquisas Energéticas e Nucleares, Universidade de São Paulo, São Paulo, 146p.

SMA, Secretaria Estadual do Meio Ambiente, 2000, Resolução SMA 03. Dispõe sobre relações que fixam a toxicidade permissível no controle ecotoxicológico de efluentes líquidos no Estado de São Paulo. Diário Oficial do Estado de São Paulo, 110(39):24, 25 fev. 2000.

SPÓSITO, R. D., 2006, Definição de alternativas de pré-tratamento de efluentes não domésticos em sistemas públicos de esgotos, utilizando o teste de avaliação da toxicidade refratária. Dissertação (Mestrado)-Escola Politécnica, Engenharia Hidráulica, Universidade de São Paulo, São Paulo, 257p.

ZAGATTO, P. A. \& BERTOLETTI, E., 2006, Ecotoxicologia aquática: princípios e aplicações. RIMA, São Carlos, SP, 478 p.

ZAGATTO, P. A. \& GOLDSTEIN, E. G., 1991, Toxicidade em águas do Estado de São Paulo. Ambiente, 5:13-20. 
